\title{
Cure versus Flow in Dispersed Chip-Underfill Materials
}

\author{
Fabien Teyssandier, Yang Y. Sun, Ching P. Wong, Brian J. Love*
}

The relative stability of chip-underfill composite materials was modeled as a function of glass filler concentration between 10 and 70 wt.-\%, filler particle size (between 5 and 25 microns), and the curing temperature of the resin $\left(150 \mathrm{vs} .180^{\circ} \mathrm{C}\right)$, yielding different dynamic viscosity profiles. The stability was gauged using a modified sigmoidal chemorheology model for the dynamic viscosity, and incorporating the time-dependent viscosity into a model for Stokes' law of sedimentation. We also incorporated a hindered sedimentation term, due to filler concentration due to the higher loadings. Several important findings were observed. First, it appears to be the high concentration of filler that is maintaining the stability of these dispersions during cure. Smaller concentrations of the same particles were predicted to have a larger sedimentation velocity leading to stratification in the resin with time. Second, higher cure temperatures led to a shorter period of sedimentation in a pre-cured state and resulted in less sedimentation, even though there was probably a slightly smaller viscosity in the pre-cured condition. While these process models adequately describe the physics of the competitive processes of cure and sedimentation, a full picture may be incomplete without a larger determination of how this also affects polymerization shrinkage and residual shear stress upon cure.

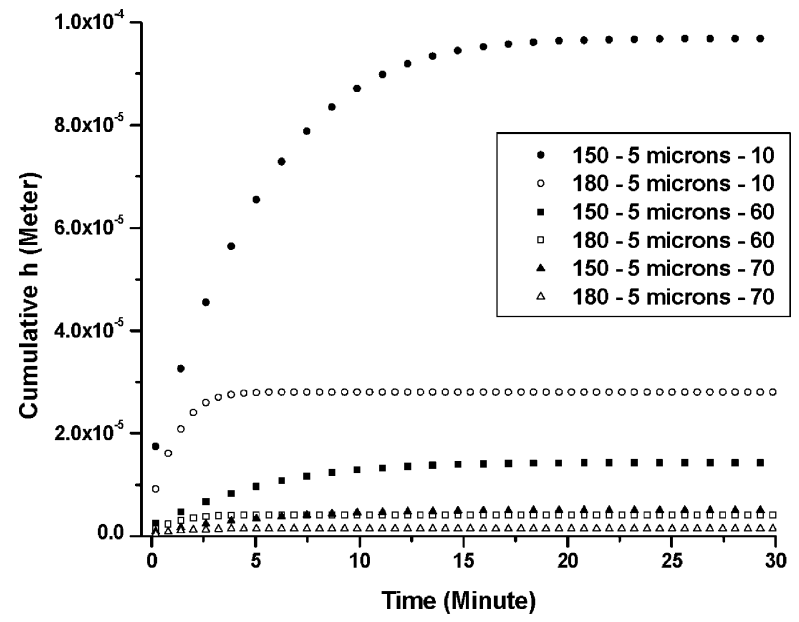

F. Teyssandier, B. J. Love

Department of Materials Science and Engineering, University of Michigan, Ann Arbor, MI 48109

E-mail: bjlove@umich.edu

B. J. Love

Department of Biomedical Engineering, University of Michigan, Ann Arbor, MI 48109

B. J. Love

Department of Biologic and Materials Sciences (Dentistry),

University of Michigan, Ann Arbor, Ml 48109

Y. Y. Sun, C. P. Wong

School of Materials Science and Engineering, Georgia Institute of

Technology, Atlanta, GA 30332

\section{Introduction}

Sedimentation and solidification often occur simultaneously and their interaction can create microstructures that have functional gradients. The presence of particles and other inclusions can also trigger liquid solidification through either crystallization or polymerization. Examples include sedimentation in cross-linking pre-polymeric resin mixtures ${ }^{[1-6]}$ and in slushy fluids near their freezing points or freezing zones. ${ }^{[7]}$ Examples of more concentrated suspensions where this is important include chip-underfill materials for flip-chip packaging ${ }^{[8-12]}$ and in ceramic laser 
sintered products dispersed with polymeric dielectric matrices and binders. ${ }^{[13,14]}$

The development of functionally-graded composites, whether intended or not, offers the potential to link transport models of particle movement in dispersions with physical models of dynamic chemorheology. This melding of physical models requires measurements or interpretations of how particle size, viscosity, and driving force are coupled during dynamic experiments.

The simplest sedimentation models have commonly invoked Stokes' law to describe particle concentration gradients, established by a driving force resulting from density differences $\left(\rho_{\pi}-\rho_{\lambda}\right)$ between a fluid of viscosity, $\eta_{0}$, and spherical particles of average diameter, $D .^{[1,15]}$ Stokes' law also assumes no fluid-particle interactions, one-dimensional transport induced by gravity or other acceleration force, and constant viscosity. The dispersed particles (assuming that they are denser) experience a driving force to settle with a Stokes' velocity, given in Equation (1):

$$
v=\frac{D^{2}\left(\rho_{p}-\rho_{l}\right) 4 g}{3 b \eta_{0} C_{e}}
$$

Where $C_{\mathrm{e}}$ is a hindered settling factor associated with the volume fraction of particles and $b$ is a constant, equal to 24 in the Stokes' creeping-flow regime. Later phases of sedimentation include transitional and compaction regimes, which are more sluggish than the Stokes' regime. The expression used here to account for hindered settling was the Richardson-Zaki relation, ${ }^{[9]} C_{e}=(1-V p)^{-4.65}$, where $V p$ is the volume fraction of particles. ${ }^{[16]}$

For non-reactive dispersions with a constant viscosity during sedimentation, Stokes' settling is commonly observed. Sedimentation in more complex dispersions has also been tracked for Bingham fluids ${ }^{[17-20]}$ and other thixotropic fluids, such as magnetite suspensions and other magnetorheological fluids, ${ }^{[21,22]}$ clays and other polymer solutions ${ }^{[23-25]}$ where non-Newtonian flow affects particle drag in solution.

Reviews by both Bicerano et al. ${ }^{[26]}$ and Metzner ${ }^{[27]}$ suggest that more-concentrated dispersion viscosity is more complicated. While Bicerno developed a particulate gelation concentration, above which dispersions display rigidity, models of reactive fluid viscosity changes during dispersion settling are less common. Among recent contributions to the literature are efforts to link sedimentation and solidification using a linearly increasing viscosity model, ${ }^{[28]}$ which might apply at early stages of conversion, and a power law model which might be more widely applicable. ${ }^{[3-5]}$ The alternative Boltzmann sigmoidal model, shown in Equation (2) for neat resins undergoing viscosity advancement, might be more representative of experimental results than the power law model: ${ }^{[29-31]}$

$$
\log \eta(t)=\log \eta_{\infty}+\frac{\log \left(\eta_{0}\right)-\log \left(\eta_{\infty}\right)}{\left(1+e^{\frac{t-t_{0}}{\Delta t}}\right)}
$$

Where $\eta_{0}$ and $\eta_{\infty}$ are the initial and terminal viscosities, $t_{0}$ is an induction time required to achieve the midpoint between $\log \eta_{0}$ and $\log \eta_{\infty}$, and $\Delta t$ is a time constant associated with the rate of viscosity rise at $t_{0}$. Here, we integrate results from chip-underfill resin conversion using a Boltzmann sigmoidal model for viscosity ${ }^{[31]}$ to Stokes' law using typical filler concentrations and process parameters to describe the relative dispersion stability.

\section{Experimental Part}

Earlier published experiments used crosslinking mixtures of glycidyl end-capped poly[(bisphenol A)-co-epichlorohydrin] and glutaric acid (Aldrich Chemical Company, Inc.) combined with a Novalac epoxy resin (LBR-6) and 1-cyanoethyl-2-undecyl-1Himozolium trimellitate (C11Z-CNS). ${ }^{[12]}$ The chemorheology experiments were originally carried out in a TA Instruments AR1000 rheometer using a parallel plate geometry stress rheometer at fixed curing temperatures $\left(150,160,170\right.$ and $\left.180^{\circ} \mathrm{C}\right)$ to simulate the heating profile conducted in underfilling.

Datasets from published rheology experiments ${ }^{[12]}$ were subsequently inputted into Microcal Origin ${ }^{\mathrm{TM}}$, which has a fourparameter sigmoidal plot function included. The model incorporates as variables the initial and final viscosities, which are functions of the resin formulation, the corresponding network densities in the cured state, and two kinetic parameters, which are functions of the initiation and propagation steps associated with polymerization. We fixed the initial viscosity for the resin in our analysis $[\log \eta(\mathrm{Pa} \cdot \mathrm{s})=-2.2]$, based on prior results; given that the only formulation difference was the filler content, our modified four-parameter model had only three variable parameters ${ }^{[31]}$. Chip-underfill materials are often made from latent cure resins that require sufficient thermal heating to trigger network formation. One time constant, $t_{0}$, we interpret as the time needed to trigger the $50 \%$ conversion from $\log \eta_{0}$. The second parameter, $\Delta t$, is a rate parameter that relates to the slope of the dynamic log viscosity curve at $t_{0}$. A shorter $\Delta t$ value would correspond to a higher rate of dynamic viscosity rise. These parameters have been determined previously for neat model chip underfill materials ${ }^{[31]}$ and are included in Table 1 for polymerization at 150 and $180^{\circ} \mathrm{C}$. The variation in sedimentation was probed in simulations incorporating the time- and temperature-dependent viscosity using two different-sized particles, and three different dispersedparticle concentrations. From these simulations, sedimentation velocities were calculated and, assuming the velocity was constant for each time step, the movement was determined by multiplying the velocity at each step by the time interval and the cumulative movement was a summation for the simulated curing time. The scope of the analysis is included in Table 2, highlighting 
Table 1. Model sigmoidal cure parameters based on Equation (2) for the underfill resins in ref. ${ }^{[12]}$ cured at 150 and $180^{\circ} \mathrm{C}$.

\begin{tabular}{|c|c|c|c|}
\hline Cure temperature & $\log \eta \infty$ & $t_{0}$ & $\Delta t$ \\
\hline${ }^{\circ} \mathrm{C}$ & $\mathrm{Pa} \cdot \mathrm{s}$ & $\min$ & $\min$ \\
\hline 150 & 4.66 & 26.1 & 10.8 \\
\hline 180 & 4.6 & 6.5 & 2.3 \\
\hline
\end{tabular}

the different cases we analyzed and each hindered settling parameter, $C_{e}$, based on the Richardson-Zaki model.

\section{Results and Discussion}

With sedimentation comes a clarified zone which grows with increasing amounts of settling and time. The interface between the clarified zone and the remaining dispersion is called the mudline, and the following figures simulate how cumulative mudline movement varies as a function of the processing and formulation parameters described earlier.

If larger filler particles $(25 \mu \mathrm{m})$ are used to reinforce these resins, significant settling is seen, as shown in Figure 1. Typically, particles smaller than $25 \mu \mathrm{m}$ are used and one can see why. Lower temperature processing (150 vs. $180^{\circ} \mathrm{C}$ ) leads to a longer induction time in which fillers are still mobile (a longer $t_{0}$ based on the sigmoidal model), yielding more clarification. The simulations also confirm

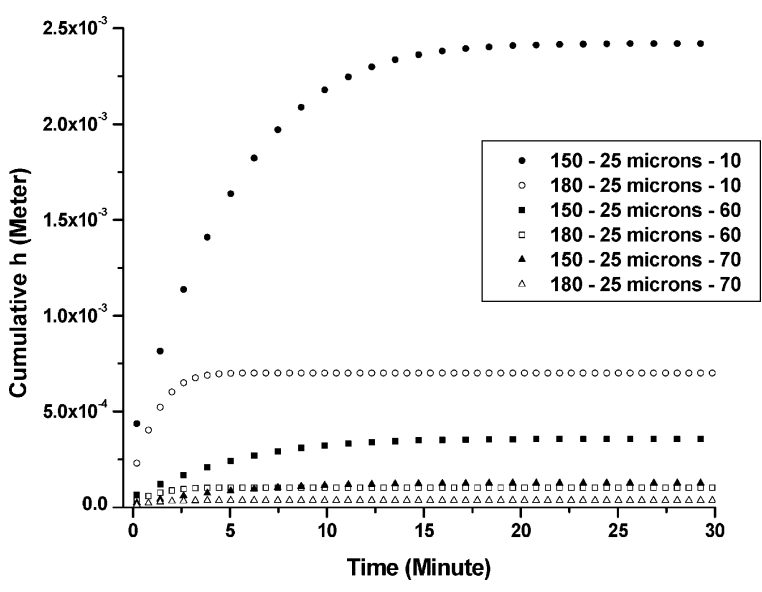

Figure 1. Cumulative mudline movement as a function of settling time for $25 \mu \mathrm{m}$ diameter particles, while the resin is polymerizing.

why larger filler concentrations are more commonly used (60-70 wt.-\%) for underfill resins, since sedimentation is more retarded at higher particle concentration. Typical underfill thicknesses are on the order of $100-500 \mu \mathrm{m}$, so larger particles have ample time to create a gradient in concentration between the top and bottom of the underfill zone. The results using the same simulation with smaller (5 $\mu \mathrm{m}$ ) particles, where the driving force for particle sedimentation is lower, are shown in Figure 2.

The justification for using larger concentrations of particles in chip-underfill materials is again confirmed by these results. There may be some intrinsic benefits in

Table 2. Hindered settling coefficients based on filler concentrations, with parameters: $\rho_{\mathrm{si}}=2.2 \mathrm{~g} \cdot \mathrm{cm}^{-3} ; \rho_{\mathrm{MMA}}=1.2 \mathrm{~g} \cdot \mathrm{cm}^{-3} ; b=24 ;$ and, $g=9.81$.

\begin{tabular}{|c|c|c|c|c|c|c|}
\hline \multirow[t]{2}{*}{ Case } & \multicolumn{2}{|c|}{ Cure temperature } & \multicolumn{2}{|c|}{ Filler diameter } & \multirow{2}{*}{$\begin{array}{c}\begin{array}{c}\text { Filler } \\
\text { concentration }\end{array} \\
\%\end{array}$} & \multirow[t]{2}{*}{$\mathrm{Ce}$} \\
\hline & $150^{\circ} \mathrm{C}$ & $180^{\circ} \mathrm{C}$ & $5 \mu \mathrm{m}$ & $25 \mu \mathrm{m}$ & & \\
\hline 1 & $\mathrm{X}$ & & $\mathrm{X}$ & & 10 & 2.38 \\
\hline 2 & & $\mathrm{X}$ & $\mathrm{X}$ & & & \\
\hline 3 & $\mathrm{X}$ & & & $\mathrm{X}$ & & \\
\hline 4 & & $\mathrm{X}$ & & $\mathrm{X}$ & & \\
\hline 5 & $\mathrm{X}$ & & $\mathrm{X}$ & & 60 & 16.11 \\
\hline 6 & & $\mathrm{X}$ & $\mathrm{X}$ & & & \\
\hline 7 & $\mathrm{X}$ & & & $\mathrm{X}$ & & \\
\hline 8 & & $\mathrm{X}$ & & $\mathrm{X}$ & & \\
\hline 9 & $\mathrm{X}$ & & $\mathrm{X}$ & & 70 & 45.49 \\
\hline 10 & & $\mathrm{X}$ & $\mathrm{X}$ & & & \\
\hline 11 & $\mathrm{X}$ & & & $\mathrm{X}$ & & \\
\hline 12 & & $\mathrm{X}$ & & $\mathrm{X}$ & & \\
\hline
\end{tabular}




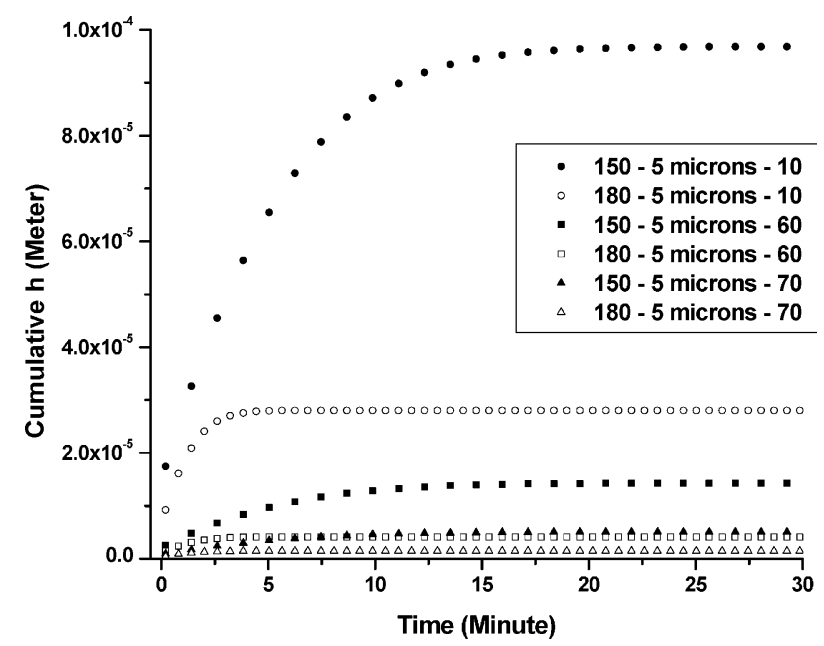

Figure 2. Cumulative mudline movement as a function of settling time for $5 \mu \mathrm{m}$ diameter particles, while the resin is polymerizing.

allowing some degree of controlled sedimentation to occur in chip-underfills. The inherent insulation resistance of the resin could be enhanced if there was a small zone of clarified resin near the top of the underfill zone. This gradient response could yield better electrical performance for components undergoing, for example, humidity cycling. Shrinkage could also be affected during underfill cure if there was variable sedimentation, which could impart a different residual stress state and affect fatigue resistance. The stress state is of the underfill in functional use is complicated enough even with a homogeneous distribution of particles; hence, a more complete understanding of what impact functional compositional gradients have on chip-underfilled devices is undefined.

\section{Conclusion}

The integration of the Boltzmann sigmoidal model for viscosity advancement with Stokes' law for sedimentation offers significant potential to accommodate predictions of dispersion stability and sedimentation potential in reactive resins that undergo a rise in viscosity during sedimentation. The integration of the models allows one to gauge how much filler content, filler size, and reaction kinetics affect dispersion stability. The integrated model has the potential to explain functional design issues, such as insulation resistance, based on sedimentation potential.

Acknowledgements: FT Acknowledges the support of fellowship funds for his visiting assignment at the University of Michigan.
Received: June 9, 2008; Accepted: August 4, 2008; DOI: 10.1002/ mame. 200800169

Keywords: chemorheology; crosslinking; epoxy; sedimentation; thermoset

[1] P. I. Dolez, A. Goff, B. J. Love, Separation Sci. Technol. 2002, 37, 2007.

[2] P. I. Dolez, C. Williams, A. Goff, B. J. Love, Underwater Technol. 2003, 25, 199.

[3] S. A. R. Hashmi, J. Appl. Polym. Sci. 2006, 99, 3009.

[4] S. A. R. Hashmi, U. K. Dwivedi, J. Polym. Res. 2007, 14, 75.

[5] S. A. R. Hashmi, U. K. Dwivedi, Polym. Eng. Sci. 2006, 46, 1660.

[6] S. Parker, M. Braden, Biomaterials 2001, 22, 2039.

[7] J. W. Gao, C. Y. Wang, J. Heat Transf. 2001, 123, 368.

[8] Z. Zhang, E. Beatty, C. P. Wong, Macromol. Chem. Phys. 2005, 206, 869.

[9] J. OQu, C. P. Wong, IEEE Electronic Components and Technology Conference, 1998, pp. 848-850.

[10] Y. Y. Sun, H. J. Jiang, L. B. Zhu, C. P. Wong, IEEE Trans. Components Packaging Technol. 2008, 31, 135.

[11] Y. Y. Sun, Z. O. Zhang, C. P. Wong, IEEE Trans. Components Packaging Technol. 2006, 29, 190.

[12] Y. Y. Sun, Z. O. Zhang, C. P. Wong, Macromol. Mater. Eng. 2005 290, 1204.

[13] T. M. G. Chu, J. W. Halloran, J. Am. Ceramic Soc. 2000, 83, 2375

[14] K. C. Wu, J. W. Halloran, J. Mater. Sci. 2005, 40, 71.

[15] W. Weber, "Sedimentation, Physicochemical Processes for Water Quality Control", Wiley, New York 1972.

[16] J. F. Richardson, W. N. Zaki, Chem. Eng. Sci. 1954, 3, 65.

[17] J. D. Chu, China Ocean Eng. 1999, 13, 171.

[18] G. Saha, N. K. Purohit, A. K. Mitra, Int. J. Mineral Process. 1992, $36,273$.

[19] T. C. Song, Y. M. Chiew, J. Hydraul. Eng. - ASCE 1997, 123, 812.

[20] A. D. Thomas, J. Rheol. 1984, 28, 658.

[21] J. Trihan, J.-H. Yoo, N. M. Wereley, S. Kotha, A. Suggs, R. Radhakrishnan, T. Sudershan, B. J. Love, "Impact of varying concentrations of nanometer-sized particles in a bidisperse magnetorheological fluid", SPIE's 10th Annual International Symposium on Smart Materials and Structures, San Diego, California 2003.

[22] N. M. Wereley, A. Chaudhuri, J. H. Yoo, S. John, S. Kotha, A. Suggs, R. Radhakrishnan, B. J. Love, T. S. Sudarshan, J. Intelligent Mater. Syst. Structures 2006, 17, 393.

[23] I. Lapides, L. Heller-Kallai, Colloid Polym. Sci. 2002, 280, 554.

[24] Y. G. Li, A. J. Mehta, J. Hydraul. Eng. - ASCE 1998, 124, 176.

[25] G. Matijasic, A. Glasnovic, Chem. Biochem. Eng. Quart. 2001, 15, 21.

[26] J. Bicerano, J. F. Douglas, D. A. Brune, J. Macromol. Sci. - Rev. Macromol. Chem. Phys. 1999, C39, 561.

[27] B. Metzner, J. Rheol. 1985, 29, 739.

[28] B. J. Love, Particulate Sci. Technol. 2004, 22, 285.

[29] F. Teyssandier, B. J. Love, Polymer 2008 (in press).

[30] B. J. Love, F. Piguet-Ruinet, F. Teyssandier, J. Polym. Sci., Part B: Polym. Phys. 2008 (in press).

[31] B. J. Love, F. Teyssandier, Y. Y. Sun, C. P. Wong, Macromol. Mater. Eng. 2008, DOI: 10.1002/mame.200800170. 